\title{
Subtotal Cholecystectomies During Acute Cholecystitis. An Overview on Different Techniques
}

\author{
Maurizio Mannino ${ }^{1}$, Adriana Toro ${ }^{2}$, Michele Teodoro ${ }^{1}$, Isidoro Di Carlo ${ }^{1}$
}

'Department of Surgical Sciences and Advanced Technologies "GF Ingrassia", University of Catania, Cannizzaro Hospital, Catania, Italy

2Department of Surgery, Augusta Hospital, (SR), Italy

\section{ABSTRACT}

Although laparoscopic cholecystectomy is a well standardized technique, subtotal cholecystectomy is still a valid option in those cases in which a complete cholecystectomy is not feasible due to the anatomic conditions given by the underlying inflammatory status or when the absence of the Critical view of Safety (CVS) make unsafe to go on a complete operation. Various techniques are described to perform a subtotal cholecystectomy, both open and laparoscopic.

Key words: subtotal cholecystectomy, laparoscopy

\section{BACKGROUND}

The term "subtotal" is still debated in literature and many authors give different meaning to it.

A consensus on how long should be the residuating infundibulum after the completion of the subtotal cholecystectomy is still lacking.

Furthermore, although various tecnhiques have been described, an algorythm on which one is the best to use in each situations does not exist.

\section{LETTER TO THE EDITORS}

A first description of what it seems a partial cholecystectomy dates back to 1898, when Hans Kehr during a surgery for an acute cholecystitis removed the gallbladder such that "the hardened posterior wall and the part of the bladder lying next to the cystic duct remained" (1).

The first article describing a subtotal cholecystectomy technique dates back to 1955 (2), while the first describing a subtotal laparoscopic cholecystectomy dates back to 1995 (3). So, although the procedure was described quite along time ago, still today the definition of what "subtotal" means is not universally accepted and some important steps are yet not standardized.

The excision of anterior wall, the excision of the posterior wall, the 
coagulation of mucosa, the closure of gallbladder stamp or the closure of the cystic duct are all methods, alone or in combination, to perform a subtotal cholecystectomy.

Our group standardized an open technique in which the maximum distance from the cystic duct should not exceed $1 \mathrm{~cm}$ of length and the remnants of the posterior and the anterior wall of the gallbladder are crouched by a running double suture (4). Although the technique has been described for open surgery, it can be performed laparoscopically following the same steps. In literature we can found many authors performing a kind of subtotal leaving in place more than $1 \mathrm{~cm}$ of gallbladder wall. This have to be defined a partial cholecystectomy. This technique have the great risk to leave in place stones or, as result of large wall left in situ, new formated stones.

The "Fenestrating" technique is another technique described in literature (5). In this technique technique the free peritonealized part of the gallbladder is excised while the lower portion of the infundibulum is left in situ and the mucosa usually ablated. The cystic duct may be closed from the inner part using a purse-string suture (5).

Bickel and Shtamler described another technique to perform a subtotal cholecystectomy involving the excision of the anterior wall, but not of the posterior, the coagulation of mucosa, the closure of the cystic duct but not of the gallbladder stump and the insertion of a routine drainage (6).

These two techniques have a risk of common bile duct (CBD) damage due to the proximity of the cystic duct consequent to the inflammation. So the closure of cystic duct from inside the gallbladder can be source of risk for the integrity of the CBD.

All the considered techniques can have as complication a post-op bile leakage, it is usually a minor complication but can be a great problem in a limited number of cases. While for none of them the bile duct injury should be considered, because it is the main complication the usage of a partial cholecystectomy technique must avoid.

In our knowledge only partial review or metaanalysis have been performed $(5,7,8)$ not considering all the possible techniques (all of them can be performed laparoscopically or with traditional open surgery), leaving still open the debate on which one, considering the amount of complications, has to be considered the safest technique.

\section{Ethics approval and consent to participate}

Not applicable

\section{Consent for publication}

Not applicable

\section{Availability of data and material}

Data supporting the present findings can be obtained, after obtaining permission from the University of Catania.

\section{Competing interests}

The authors declare that they have no competing interests.

\section{Funding}

The authors received no financial support for the research, authorship, and publication of this article.

\section{Authors' contributions}

$\mathrm{MM}$ and $\mathrm{AT}$ were major contributors to writing the manuscript. MM, and TM acquired the data. AT, MM and TM analysed and interpreted the data. IDC, CF, SM, $\mathrm{AL}$ and CF performed a critical revision of the manuscript. All authors read and approved the final manuscript.

Acknowledgements: None.

\section{Declaration of conflicting interests}

The authors declared no potential conflicts of interest with respect to the research, authorship, and/or publication of this article.

\section{REFERENCES}

1. Kehr H. Introduction to the Differential Diagnosis of the Separate Forms of Gallstone Disease: Based upon His Own Experience Gained from 433 Laparotomies for Gallstones.Philedelphia: P Blakiston's Son and Co; 1901.

2. Madding GF. Subtotal cholecystectomy in acute cholecystitis. Am J Surg. 1955;89(3):604-7.

3. Crosthwaite G, McKay C, Anderson JR. Laparoscopic subtotal cholecystectomy. J R Coll Surg Edinb. 1995;40(1):20-1.

4. Di Carlo I, Pulvirenti E, Toro A, Corsale G. Modified subtotal chole- 
cystectomy: results of a laparotomy procedure during the laparoscopic era. World J Surg. 2009;33(3):520-5.

5. Strasberg SM, Pucci MJ, Brunt LM, Deziel DJ. Subtotal Cholecystectomy-"Fenestrating" vs "Reconstituting" Subtypes and the Prevention of Bile Duct Injury: Definition of the Optimal Procedure in Difficult Operative Conditions. J Am Coll Surg. 2016; 222(1):89-96

6. Bickel A, Shtamler B. Laparoscopic subtotal cholecystectomy. J
Laparoendosc Surg. 1993;3(4):365-7.

7. Henneman D, da Costa DW, Vrouenraets BC, van Wagensveld BA, Lagarde SM. Laparoscopic partial cholecystectomy for the difficult gallbladder: a systematic review. Surg Endosc. 2013; 27(2):351-8.

8. Elshaer M, Gravante G, Thomas K, Sorge R, Al-Hamali S, Ebdewi H. Subtotal cholecystectomy for "difficult gallbladders": systematic review and meta-analysis. JAMA Surg. 2015;150(2):159-68. 